\title{
TP0463518, a Novel Prolyl Hydroxylase Inhibitor, Specifically Induces Erythropoietin Production in the Liver ${ }^{\mathrm{S}}$
}

\author{
- Sota Kato, Nagahiro Ochiai, Hiroki Takano, Fusayo lo, Noriko Takayama, \\ Hiroko Koretsune, Ei-ichi Kunioka, Saeko Uchida, and Koji Yamamoto \\ Pharmacology Laboratories (S.K., N.O., F.I., N.T., H.K., E.-i.K., S.U., K.Y.) and Drug Safety and Pharmacokinetics Laboratories \\ (H.T.), Taisho Pharmaceutical, Saitama, Japan
}

Received April 21, 2019; accepted October 2, 2019

\begin{abstract}
Prolyl hydroxylase (PHD) $1 / 2 / 3$ pan inhibitors are known to potentially induce erythropoietin (EPO) production in both the kidney and liver. The 2-[[1-[[6-(4-chlorophenoxy)pyridin-3-yl] methyl]-4-hydroxy-6-oxo-2,3-dihydropyridine-5-carbonyl]amino] acetic acid (TP0463518) is a novel PHD 1/2/3 pan inhibitor; however, the main source of EPO production after TP0463518 administration remained to be investigated. We examined the effect of TP0463518 in inducing EPO production in the kidney and liver by measuring the hypoxia-inducible factor $2 \alpha(\mathrm{HIF}-2 \alpha)$, EPO mRNA, and serum EPO levels in normal and bilaterally nephrectomized rats. Furthermore, we examined whether liverderived EPO improved anemia in 5/6 nephrectomized (5/6 Nx) rats. TP0463518 scarcely increased the HIF-2 $\alpha$ and EPO mRNA expression levels in the kidney cortex, whereas oral administration of TP0463518 at $40 \mathrm{mg} / \mathrm{kg}$ dramatically increased the HIF$2 \alpha$ level from 0.27 to $1.53 \mathrm{fmol} / \mathrm{mg}$ and the EPO mRNA expression level by 1300 -fold in the livers of healthy rats. After administration of TP0463518 at $20 \mathrm{mg} / \mathrm{kg}$, the total EPO mRNA expression level in the whole liver was 22-fold that in the whole kidney. In bilaterally nephrectomized rats, TP0463518 raised the serum EPO concentration from 0 to $180 \mathrm{pg} / \mathrm{ml}$ at $20 \mathrm{mg} / \mathrm{kg}$.
\end{abstract}

Furthermore, repeated administration of TP0463518 at $10 \mathrm{mg} / \mathrm{kg}$ increased the reticulocyte count in $5 / 6 \mathrm{Nx}$ rats on day 7 and raised the hemoglobin level on day 14 . The present study revealed that TP0463518 specifically induced EPO production in the liver and improved anemia. The characteristic feature of TP0463518 would lead to not only a more detailed understanding of the PHD-HIF2 $\alpha$-EPO pathway in erythropoiesis, but a new therapeutic alternative for renal anemia.

\section{SIGNIFICANCE STATEMENT}

Prolyl hydroxylase (PHD) 1/2/3 pan inhibitors are known to potentially induce erythropoietin (EPO) production in both the kidney and liver; however, their effects on renal EPO production have been shown to vary depending on the experimental conditions. The authors found that 2-[[1-[[6-(4-chlorophenoxy)pyridin3-yl]methyl]-4-hydroxy-6-oxo-2,3-dihydropyridine-5-carbonyl] amino]acetic acid (TP0463518), a PHD 1/2/3 pan inhibitor, specifically induced EPO production in the liver and that the liver-derived EPO was pharmacologically effective. Investigation of the effects of TP0463518 may pave the way for the development of a new therapeutic alternative for renal anemia patients.

\section{Introduction}

Erythropoietin (EPO) is a hematopoietic factor that acts on the EPO receptor to activate the Janus activating kinase 2 signaling cascade and stimulate the differentiation of erythroid progenitor cells into erythrocytes (Koury and Haase, 2015; Kuhrt and Wojchowski, 2015). In neonates and infants, EPO is mainly synthesized in the liver (Zanjani et al., 1981; Dame et al., 1998). During development, the main site of EPO production shifts from the fetal liver to the adult kidney (Rankin et al., 2007; Kapitsinou et al., 2010). The kidney thus becomes the main source of EPO in adults and is considered to be the most sensitive organ to hypoxia (Haase, 2017). Importantly, in nephropathy, renal EPO-producing cells transform

The authors are employees of Taisho Pharmaceutical, and the company provided financial support for this work.

https://doi.org/10.1124/jpet.119.258731.

S This article has supplemental material available at jpet.aspetjournals.org. to myofibroblasts and lose their EPO-producing capacity (Asada et al., 2011; Souma et al., 2013). As a result, patients with severe kidney diseases cannot produce sufficient EPO to maintain the hemoglobin level, and consequently develop renal anemia.

Expression of EPO is regulated by hypoxia-inducible factor (HIF)-2 $\alpha$, a master transcriptional regulator of the response to hypoxia. Under the normoxic condition, proline residues of HIF- $2 \alpha$ are hydroxylated by HIF prolyl hydroxylase (PHD), which utilizes oxygen as a substrate (Hirsilä et al., 2003; Dao et al., 2009; Pappalardi et al., 2011). Hydroxylated HIF-2 $\alpha$ is recognized by a ubiquitin ligase, von Hippel-Lindau protein, and degraded through the ubiquitin-proteasome pathway (Maxwell et al., 1999; Jaakkola et al., 2001). Under the hypoxic condition, the PHD activity is suppressed due to depletion of oxygen, and HIF- $2 \alpha$ escapes hydroxylation and subsequent degradation. Stabilized HIF- $\alpha$ binds to the hypoxia response element together with CREB-binding protein/p300 and the constitutively active $\operatorname{HIF} \beta$ to upregulate EPO in both the

ABBREVIATIONS: 5/6 Nx, 5/6 nephrectomized; BNx, bilaterally nephrectomized; DMOG, dimethyloxaloylglycine; EPO, erythropoietin; HIF, hypoxia inducible factor; PHD, prolyl hydroxylase; SD, Sprague-Dawley; TP0463518, 2-[[1-[[6-(4-chlorophenoxy)pyridin-3-yl]methyl]-4-hydroxy-6oxo-2,3-dihydropyridine-5-carbonyl]amino]acetic acid. 
kidney and liver (Haase, 2006). Three isoforms of PHD have been recognized, as follows: PHD1, PHD2, and PHD3. Genetically, deletion of the PHD2 gene alone increases the renal EPO production and hemoglobin levels (Takeda et al., 2008; Minamishima et al., 2009), and individuals with loss-offunction mutations in PHD2 show elevated blood hemoglobin levels (Percy et al., 2006, 2007; Ladroue et al., 2008). In contrast, triple knockout of PHD1/2/3 dramatically increases hepatic EPO expression (Minamishima and Kaelin, 2010; Tojo et al., 2015). Therefore, it is thought that PHD2 is involved in renal EPO production, whereas all the PHDs function cooperatively to regulate hepatic EPO expression.

Based on the finding that PHD inhibitors exert erythropoietic effects via inducing HIF- $2 \alpha$ stabilization and EPO production, phase III trials of PHD inhibitors as alternative erythropoiesis-stimulating agents are underway. All the PHD inhibitors under clinical trials to date inhibit all three PHD isoforms and potentially induce EPO in both the kidney and liver (Flamme et al., 2014; Ariazi et al., 2017; Kato et al., 2018). However, the effects of the PHD inhibitors on the renal EPO production seem to vary depending on the type of PHD inhibitor used and the experimental conditions of nephropathy. When unilateral ureteral obstruction was induced in knockout mice lacking PHD1/2/3, myofibroblast-transformed renal EPO-producing cells proliferated in the damaged kidney and higher levels of EPO mRNA were found in the damaged kidney than in the healthy kidney (Souma et al., 2016). In contrast, the increase of the renal EPO mRNA expression induced by a PHD inhibitor was significantly lower in gentamicin-induced nephropathic rats as compared with healthy control rats, possibly due to the loss of the kidney parenchyma (Flamme et al., 2014). In contrast, the amount of liver-derived EPO induced by PHD inhibitors remains unchanged regardless of the stage of nephropathy. Therefore, we considered it important to conduct a detailed investigation of whether an inhibitor would act mainly on the kidney or on the liver.

The 2-[[1-[[6-(4-chlorophenoxy)pyridin-3-yl]methyl]-4-hydroxy-6oxo-2,3-dihydropyridine-5-carbonyl]amino]acetic acid (TP0463518) is a competitive PHD1/2/3 pan inhibitor and increases the serum EPO levels in mice, rats, and monkeys (Kato et al., 2018). Because our previous study indicated that the serum EPO levels in 5/6 nephrectomized (5/6 Nx) Sprague-Dawley (SD) rats were comparable to those in healthy SD rats for the same plasma TP0463518 concentrations, we hypothesized that TP0463518 could increase hepatic EPO production without increasing EPO production in the kidney. In this study, we examined the production of EPO after administration of TP0463518 using healthy and bilaterally nephrectomized $(\mathrm{BNx})$ rats, and also examined whether the liver-derived EPO improved the anemia in 5/6 Nx rats. Our study demonstrated that TP0463518 stabilized HIF- $2 \alpha$ only in the liver and induced liver-derived EPO production, irrespective of the stage of nephropathy. Based on the present findings, we propose that TP0463518 could be developed as a new therapeutic alternative for patients with renal anemia.

\section{Materials and Methods}

Compound. TP0463518 was synthesized at Taisho Pharmaceutical, according to a previously described method (Hamada et al., 2018).
Animal Protocol. All animal protocols were approved by the Animal Committee of Taisho Pharmaceutical, and all the animal experiments were conducted under the approval of the committee. The room temperature and humidity were maintained at $23 \pm 3{ }^{\circ} \mathrm{C}$ and $50 \% \pm 20 \%$, respectively, with a light-dark cycle of $12 / 12$ hours. Food and water were made freely available to the animals.

Seven-week-old SD rats (Japan SLC, Hamamatsu, Shizuoka, Japan) received oral TP0463518 administration. The rats were anesthetized, and blood samples were collected at each time point. Then the rats were euthanized, and the kidneys and liver were removed. The right kidney of the SD rats was divided into the inferior half and superior half. The inferior half (whole kidney) was cut into 3mm-thick slices. All of the sliced whole kidney, specimens of the left kidney cortex, and specimens of the liver were immersed in RNAlater solution overnight at $4^{\circ} \mathrm{C}$ and then stored at $-80^{\circ} \mathrm{C}$ until the mRNA extraction. The superior half of the right kidney and specimens of the liver were stored at $-80^{\circ} \mathrm{C}$ to determine the organ TP0463518 exposure. Specimens of the left kidney cortex and of the liver were snap-frozen in liquid $\mathrm{N} 2$ and stored at $-80^{\circ} \mathrm{C}$ until measurement of the organ levels of HIF- $2 \alpha$. The blood samples were mixed with EDTA. The samples were then centrifuged $\left(4^{\circ} \mathrm{C}, 2130 g, 10\right.$ minutes $)$ to obtain plasma.

Bilateral nephrectomy was performed in 7-week-old SD rats under isoflurane and xylocaine anesthesia. A midline incision was made, and the pedicle of the left kidney was ligated at two sites. The left kidney was removed by cutting between the two ligated sites. Then the right kidney was also removed in the same manner as the left kidney. The cecum and small intestine were returned to their original positions. Then, after suturing the fascia, the skin incision was closed with Aron Alpha. The rats were laid on a heat pad at $37^{\circ} \mathrm{C}$ during and after the surgery and observed until they regained consciousness. The sham rats were operated in the same way, except that the steps from ligation of the renal pedicle to removal of the kidneys were skipped. At 16 hours after the operation, the rats were administered TP0463518. In the first study, the $\mathrm{BNx}$ rats were euthanized at 4 hours after administration, and the kidneys (sham rats) and liver (sham and BNx rats) were removed to measure the EPO mRNA expression level. In the second study, blood was collected at 8 hours after administration from the subclavian vein under anesthesia. The samples were then centrifuged (room temperature, $2130 \mathrm{~g}, 10$ minutes) to obtain serum.

In the $5 / 6 \mathrm{Nx}$ rats, two-thirds of the left kidneys of the SD rats were resected when the rats were 4 weeks old, and the right kidney was removed when the animals were 5 weeks old. As they became 10 weeks old, the $5 / 6 \mathrm{Nx}$ rats were randomly assigned to the experimental groups, while ensuring that the variance and mean hemoglobin levels remained balanced among the groups. In the first study, the $5 / 6 \mathrm{Nx}$ rats were euthanized at 2 hours after administration of TP0463518, and the remnant kidney and liver were removed. Specimens of the kidney cortex and liver were stored in RNAlater solution to measure the EPO mRNA. In the second study, the $5 / 6 \mathrm{Nx}$ rats received oral vehicle or TP0463518 administration once daily for 14 days. Blood was collected from the tail vein on days 0,7 , and 14 . The blood samples were mixed with EDTA and analyzed using ADVIA 120 (Siemens Healthcare Diagnostics, Tokyo, Japan).

Cellular Assay. HepG2 and H4-II-E-C3 carcinoma cell lines were seeded in 48 -well plate at $2.0 \times 10^{5}$ cells $/$ well or $1.2 \times 10^{5}$ cells/well, respectively, in Dulbecco's modified Eagle's medium (GIBCO) supplemented with $10 \%$ fetal bovine serum (GIBCO). Twenty-four hours after seeding, the medium was changed to $100 \mu \mathrm{l}$ opti-MEM (GIBCO) containing various concentrations of TP0463518. The cells were incubated for 24 hours, and then the mRNA was extracted to measure EPO mRNA expression. Another plate of cells was incubated for 72 hours, and then the media were collected to measure EPO concentration in the media.

Measurement of EPO mRNA. The mRNA in the cells, renal cortex, and liver was extracted using RNeasy Plus Mini Kit (Qiagen), according to the manufacturer's manual. The mRNA from the whole kidney was prepared as follows. The inferior half of the right kidney 
was homogenized with Tissue Lyser in $1200 \mu \mathrm{l}$ buffer RLT. Then, $150 \mu \mathrm{l}$ homogenate was added to $500 \mu \mathrm{l}$ buffer RLT. The remaining steps were carried out according to the manual. Reverse-transcription and real-time quantitative polymerase chain reaction were carried out according to the standard methods (Tea et al., 2009; Wigestrand et al., 2011). The primer sequences are listed in Table 1 . In the case of EPO expression below the detection limit (three cases in liver in all the experiments), the EPO expression was calculated by substituting 40 for the cycle threshold value.

Relative EPO mRNA expressions in the cells, renal cortex, and liver were calculated as the ratios to those in the vehicle group. The total EPO mRNA expressions in the whole organs were calculated using a modification of the method described by Eckardt et al. (1992). The total EPO mRNA expressions were calculated as shown in eq. 1.

Total EPO mRNA expression $=\frac{(\text { total }) \text { EPO } m R N A}{(\text { total }) H P R T \text { mRNA }} \times \frac{H P R T \text { mRNA }}{R N A \text { amount }}$ $\times \frac{R N A \text { amount }}{\text { organ weight }} \times$ organ weight

For EPO mRNA/hypoxanthine-guanine phosphoribosyltransferase mRNA and organ weight, measured values were substituted. For RNA amount/organ weight, the values were cited from the previous study (Eckardt et al., 1992). Our preliminary data indicated that the hypoxanthine-guanine phosphoribosyltransferase mRNA/RNA amount was almost the same between the kidney and liver, as reported previously (Vandesompele et al., 2002). Therefore, eq. 1 could be converted to eq. 2, as follows, where $k$ is a constant, such that the total EPO mRNA expression in the kidney is 1 .

$$
\begin{aligned}
& \text { Total EPO mRNA expression }=\frac{E P O ~ m R N A}{H P R T \text { mRNA }} \times \frac{R N A \text { amount }}{\text { organ weight }} \\
& \quad \times \text { organ weight } \times k
\end{aligned}
$$

Determination of HIF-2 $\alpha$ Expression in the Kidney Cortex and Liver. The kidney cortices and livers were homogenized in 10 volumes of protein extraction buffer $(20 \mathrm{mM}$ Tris-HCl, $\mathrm{pH}$ 8.0, $1.5 \mathrm{mM}$ $\mathrm{MgCl}_{2}, 420 \mathrm{mM} \mathrm{NaCl}, 25$ vol\% glycerol, $0.2 \mathrm{mM}$ EDTA, 0.5 vol \% IGEPAL CA-630, 1 mM dithiothreitol, $1 \mathrm{mM}$ phenylmethylsulfonyl fluoride, and proteinase inhibitor cocktail), and the homogenates were centrifuged $\left(4^{\circ} \mathrm{C}, 15,000 \mathrm{~g}, 10\right.$ minutes $)$ to prepare the protein extracts. The extracts were mixed with sample buffer and heated at $96^{\circ} \mathrm{C}$ for 5 minutes. Then $140 \mu \mathrm{g}$ protein extracts were applied to SDS-PAGE. The gels were stained with Coomassie Brilliant Blue, and an area of 90-120 kDa was cut out and dried. Cysteine residues in the protein of the gel were reduced at $56^{\circ} \mathrm{C}$ for 60 minutes with reduction buffer (10 $\mathrm{mM}$ dithiothreitol and $25 \mathrm{mM}$ ammonium bicarbonate) and then alkylated at room temperature for 45 minutes, protected from light, with alkylation buffer ( $55 \mathrm{mM}$ iodoacetamide and $25 \mathrm{mM}$ ammonium bicarbonate). Then the gels were dried again, and the proteins in the gels were digested with $200 \mathrm{ng} / \mathrm{ml}$ trypsin at $37^{\circ} \mathrm{C}$ for 15 hours. After the digestion, peptides were extracted from the gels with extraction buffer (50\% acetonitrile and 1\% formic acid). Stable isotope-labeled peptides (GQVVS[Gly $\left.\left({ }^{13} \mathrm{C}_{2} ;{ }^{15} \mathrm{~N}\right)\right] \mathrm{QYR}$ and LAISF $\left[\right.$ Leu $\left.\left({ }^{13} \mathrm{C}_{6} ;{ }^{15} \mathrm{~N}\right)\right] \mathrm{R}$ ) were added to the peptide extracts as an external standard. The peptide extracts were separated with DiNa nano-LC system (KYA Technologies, Tokyo, Japan) and analyzed with QTRAP 5500 (AB Sciex LLC, Framingham, MA). A standard curve was prepared with unlabeled peptides.

Determination of EPO in Serum and Medium. The EPO levels in serum and medium were measured using a commercially available EPO ELISA kit (rat, BioLegend, San Diego, CA; human, Stemcell Technologies, Vancouver, Canada), according to the manufacturer's manual. EPO levels below the detection limits were considered as zero for the purpose of analysis.

Determination of the TP0463518 Concentration in the Kidney, Liver, and Plasma. The TP0463518 concentrations in
TABLE 1

Primer sequences

\begin{tabular}{lll}
\hline & Gene & \multicolumn{1}{c}{ Sequence $\left(5^{\prime}\right.$ to $\left.3^{\prime}\right)$} \\
\hline Human & $18 \mathrm{~S}$ & GTAACCCGTTGAACCCATT \\
& CCATCCAATCGGTAGTAGCG \\
& GAGGCCGAGAATATCACGACGGG \\
Rat & TPCCCGACCTCCATCCTCTTCCAG \\
& EPO & TTGTTGGATATGCCCTTGACT \\
& CCGCTGTCTTTAGGCTTTG \\
& ACCAGAGAGTCTTCAGCTTCA \\
& GAGGCGACATCAATTCCTTC \\
\hline
\end{tabular}

18S, 18S rRNA; HPRT, hypoxanthine guanine phosphoribosyltransferase.

the kidney, liver, and plasma were measured by liquid chromatography-tandem mass spectrometry, using the LC-20AD high-pressure liquid chromatography system (Shimadzu, Kyoto, Japan) and API4000 (AB Sciex LLC).

Statistics. Data are shown as the means \pm S.E.M. or means \pm S.D. As the EPO mRNA expression levels increased exponentially, the means and S.E.M. were calculated for logarithmically transformed values of EPO mRNA. The statistical significances of differences were determined using the Student's $t$ test or Dunnett's test, using SAS 9.2. Statistical significance was defined as $P<0.05$.

\section{Results}

TP0463518 Only Slightly Increases Renal EPO Production in Healthy Rats. To examine whether TP0463518 exerts EPO-producing effect in the kidney, we addressed the effect of TP0463518 on the HIF-2 $\alpha$ and EPO mRNA expression levels in the kidney cortex after administration of $20 \mathrm{mg} / \mathrm{kg}$ TP0463518. TP0463518 failed to increase the HIF-2 $\alpha$ level in the kidney cortex for 24 hours (Fig. 1A). The EPO mRNA expression in the kidney cortex increased slightly at 2 and 4 hours after the TP0463518 administration and returned to the baseline level thereafter (Fig. 1B). Analysis of the dose dependence of the effect of TP0463518 on the HIF- $2 \alpha$ and EPO mRNA expressions at 4 hours showed that TP0463518 did not change the HIF-2 $\alpha$ levels up to $40 \mathrm{mg} / \mathrm{kg}$ (Fig. 1C). TP0463518 did not change the EPO mRNA levels up to $10 \mathrm{mg} / \mathrm{kg}$, except thereafter, slightly, but significantly increased the EPO mRNA expression level at $20 \mathrm{mg} / \mathrm{kg}$ or more (Fig. 1D). These results indicated that TP0463518 only slightly induced EPO mRNA expression in the kidney cortex, but this effect was transient and HIF $2 \alpha$-independent.

We also addressed the effect of dimethyloxaloylglycine (DMOG), another PHD inhibitor, on the EPO mRNA expression in the kidney cortex at 4 hours after administration of 60 and $600 \mathrm{mg} / \mathrm{kg}$. The EPO mRNA levels did not change at $60 \mathrm{mg} / \mathrm{kg}$ DMOG, but slightly increased at $600 \mathrm{mg} / \mathrm{kg}$ (Supplemental Fig. 1A).

TP0463518 Increases Hepatic EPO Production in Healthy Rats. We next measured the HIF- $2 \alpha$ and EPO mRNA expression levels in the liver to examine whether TP0463518 exerts EPO-producing effect in the liver. HIF2 $\alpha$ markedly increased in the liver at 1 hour after TP0463518 administration and peaked at 2 hours (Fig. 2A). At 2 hours postadministration, TP0463518 significantly increased liver HIF $2 \alpha$ at $5 \mathrm{mg} / \mathrm{kg}$ or more in a dose-dependent manner; the increase in HIF- $2 \alpha$ expression at $40 \mathrm{mg} / \mathrm{kg}$ TP0463518 was 5.7 -fold higher from $0.27 \mathrm{fmol} / \mathrm{mg}$ in the vehicle-treated group to $1.53 \mathrm{fmol} / \mathrm{mg}$ in the $40 \mathrm{mg} / \mathrm{kg}$ TP0463518-treated group (Fig. 2C). Remarkably, the EPO mRNA expression level 

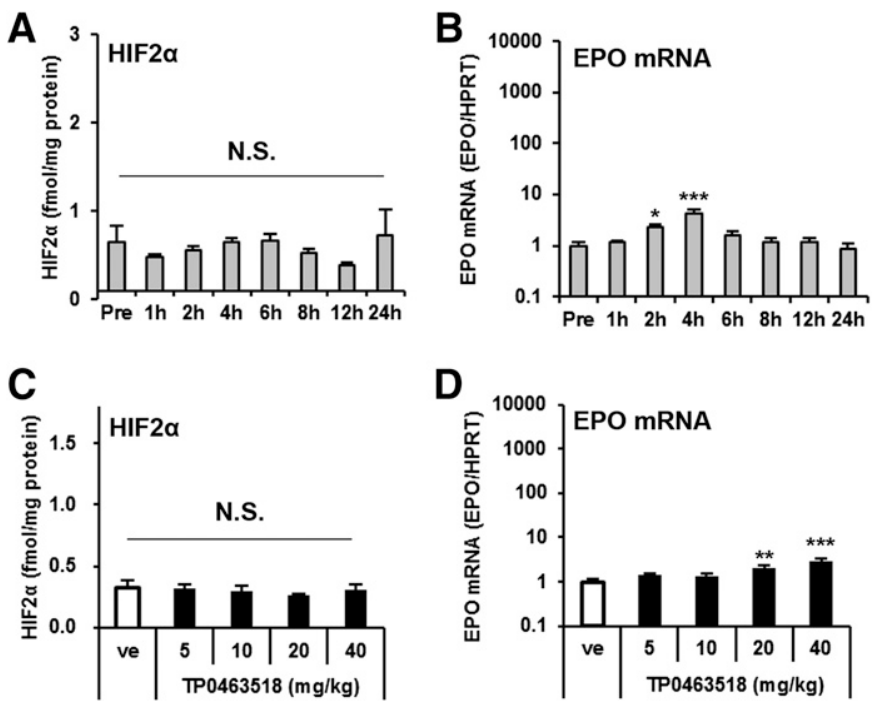

Fig. 1. TP0463518 scarcely increases the expressions of HIF-2 $\alpha$ and EPO mRNA in the kidney cortex. (A and B) Time-course study of HIF-2 $\alpha$ stabilization and EPO mRNA expression after administration of $20 \mathrm{mg} / \mathrm{kg}$ TP0463518. TP0463518 failed to increase the HIF-2 $\alpha$ level in the kidney cortex up to 24 hours (A). A slight and transient increase of the EPO mRNA expression level was observed at 2 and 4 hours postadministration (B). (C and D) Dose-titration study of HIF-2 $\alpha$ stabilization and EPO mRNA expression at 4 hours postadministration. TP0463518 failed to increase the HIF-2 $\alpha$ level in the kidney cortex up to $40 \mathrm{mg} / \mathrm{kg}$ (C). EPO mRNA expression remained stable up to $10 \mathrm{mg} / \mathrm{kg}$, with slight, but significant increase at $20 \mathrm{mg} / \mathrm{kg}$ or more (D). Data are represented as the means \pm S.E.M. $n=5$ to 6 . Dunnett's multiple comparison test was used to compare the TP0463518-treated groups and the corresponding control groups (the nontreated Pre group in the time-course study and the vehicletreated group in the dose-dependent study). N.S., not statistically significant; $* P<0.05 ; * * P<0.01 ; * * * P<0.001$

increased dramatically following administration of TP0463518 and remained high for over 24 hours, with the peak at 4 hours post-TP0463518 administration (Fig. 2B). At 4 hours postadministration, the increase of the EPO mRNA level induced by TP0463518 was dose-dependent, and the expression level in the $40 \mathrm{mg} / \mathrm{kg}$ TP0463518-treated group was 1300 -fold higher than that in the vehicle-treated group (Fig. 2D).

DMOG dose-dependently increased EPO mRNA levels in the liver at 4 hours postadministration (Supplemental Fig. 1B). The increase of EPO mRNA was 7800 -fold higher in the $600 \mathrm{mg} / \mathrm{kg}$ DMOG-treated group than that in the vehicletreated group.

Total EPO mRNA Expression Levels in the Whole Liver Are Higher Than Those in the Whole Kidney. Because EPO mRNA expression in the adult rat liver is very low (Eckardt et al., 1992; Tan et al., 1992), the marked increase in the relative EPO mRNA expression level could be a result of overestimation of the mRNA levels after TP0463518 administration. We therefore estimated the total EPO mRNA expression levels in the whole liver and whole kidney by multiplying EPO mRNA levels in the liver and kidney by the organ weight and total mRNA expression amount in each organ. The total EPO mRNA expressions in each organ after TP0463518 administration were then compared in reference to the renal EPO mRNA level in the vehicletreated group set as 1 (see Materials and Methods). In the kidney, the total EPO mRNA expression level failed to increase up to $10 \mathrm{mg} / \mathrm{kg}$ TP0463518, and then slightly increased at doses of 20 and $40 \mathrm{mg} / \mathrm{kg}$ (Fig. 3). In the vehicle-treated group,
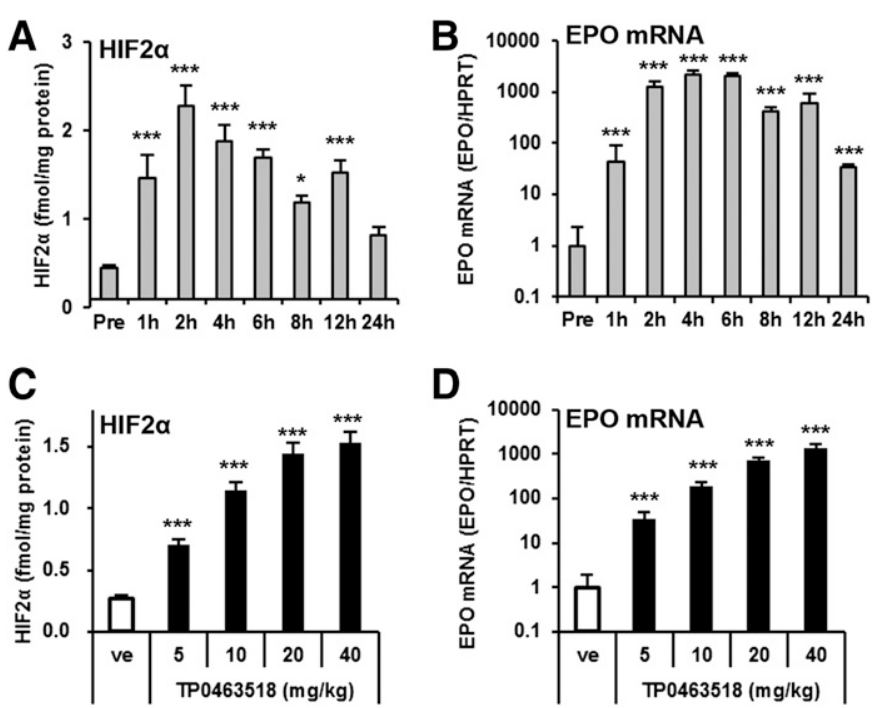

Fig. 2. TP0463518 markedly increases the expressions of HIF-2 $\alpha$ and EPO mRNA in the liver. (A and B) Time-course study of HIF- $2 \alpha$ stabilization and EPO mRNA expression after administration of $20 \mathrm{mg} / \mathrm{kg}$ TP0463518. The HIF-2 $\alpha$ level markedly increased in the liver and peaked at 2 hours postadministration (A). EPO mRNA expression dramatically increased post-TP0463518 administration and peaked at 4 hours postadministration (B). (C and D) Dose-titration study of HIF-2 $\alpha$ stabilization and EPO mRNA expression. TP0463518 administration at $5 \mathrm{mg} / \mathrm{kg}$ or more significantly increased the HIF- $2 \alpha$ level at 2 hours postadministration (C). TP0463518 caused a dramatic increase of the EPO mRNA expression in a dose-dependent manner at 4 hours postadministration (D). Data are represented as the means \pm S.E.M. $n=5$ to 6 . Dunnett's multiple comparison test was used to compare the TP0463518treated groups and the corresponding control groups (the nontreated Pre group in the time-course study and the vehicle-treated group in the dosedependent study). $* P<0.05 ; * * * P<0.001$

the total EPO mRNA expression level in the whole liver was 0.29 -fold to that in the whole kidney. Importantly, this expression became 18-fold higher in the group treated with $10 \mathrm{mg} / \mathrm{kg}$ TP0463518. Furthermore, at $20 \mathrm{mg} / \mathrm{kg}$ TP0463518, the total EPO mRNA in the whole liver was 22-fold higher than that in the whole kidney, even though the total EPO mRNA expression in the whole kidney was slightly increased under this condition. These results explicitly demonstrated that TP0463518 was considerably more potent at inducing EPO production in the liver than in the kidney.

In the $600 \mathrm{mg} / \mathrm{kg}$ DMOG-treated group, the total EPO mRNA expression levels in the whole liver were 79-fold higher than that in the whole kidney (Supplemental Fig. 2).

TP0463518 Increases the Serum EPO Levels in BNx Rats. We next examined whether the rise in the serum EPO levels after TP0463518 administration could reflect the increased EPO mRNA expression levels in the liver. We previously reported that TP0463518 increased the serum EPO levels in 5/6 Nx rats (Kato et al., 2018). However, because 5/6 $\mathrm{Nx}$ rats have a remnant kidney, we could not exclude the effect of TP463518 on the remaining kidney in the rise of the serum EPO levels. Therefore, we examined the EPO-producing effect of TP0463518 in BNx rats. TP0463518 at 10 and $20 \mathrm{mg} / \mathrm{kg}$ did not increase the EPO mRNA expression in the kidney in the sham rats (Fig. 4A), indicating that the kidney did not contribute to the rise of the serum EPO levels after TP0463518 administration in the sham rats. TP0463518 at the doses of 10 and $20 \mathrm{mg} / \mathrm{kg}$ increased the EPO mRNA expression levels in the liver of the sham rats by 56 - and 388 -fold, respectively (Fig. 4B). 


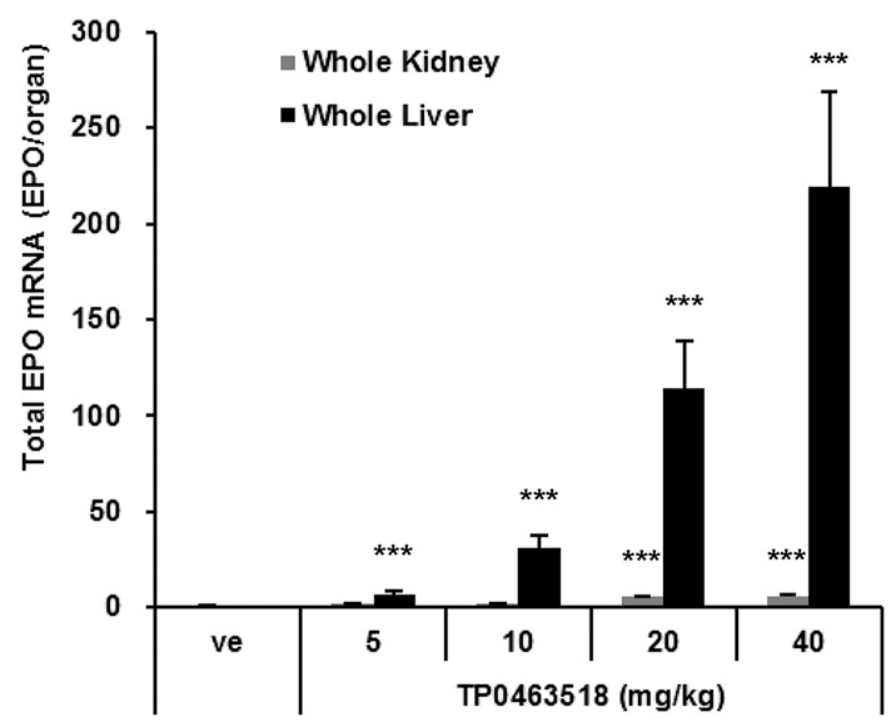

Fig. 3. Total EPO mRNA expression levels in the whole liver are higher than those in the whole kidney. Relative EPO mRNA expression at 4 hours post-TP0463518 administration was multiplied by the organ weight and the total mRNA expression amount, to determine the total EPO mRNA expression levels in the whole kidney (gray bar) and whole liver (black bar). The total EPO mRNA expression level in each organ was normalized by the renal EPO mRNA expression level in the vehicle-treated group. The total EPO mRNA expression in the whole liver was dramatically increased, whereas that in the whole kidney was scarcely increased. Data are represented as the means \pm S.E.M. $n=6$. Dunnett's multiple comparison test was used to compare the TP0463518-treated groups and the vehicle-treated groups. ${ }^{* * *} P<0.001$.

TP0463518 at the same doses also raised the EPO mRNA expression levels in the livers of the BNx rats by 127 - and 753fold, respectively, indicating that TP0463518 induces EPO mRNA expression increase in the liver even in $\mathrm{BNx}$ rats.

The serum EPO concentration in the BNx rats was below the detection limit at 24 hours after nephrectomy (Fig. 4C) because BNx rats do not have EPO secretion from the kidney. In normal rats, TP0463518 increased the serum EPO concentration in a dose-dependent manner, as previously reported (Kato et al., 2018). In the sham rats, TP0463518 increased the serum EPO concentrations from $18 \mathrm{pg} / \mathrm{ml}$ in the vehicletreated group to $71 \mathrm{pg} / \mathrm{ml}$ in the $20 \mathrm{mg} / \mathrm{kg}$ TP0463518treated group. In the BNx rats, TP0463518 at 10 and $20 \mathrm{mg} / \mathrm{kg}$ also raised the serum EPO concentrations from 0 (below detection limit) to 28 and $180 \mathrm{pg} / \mathrm{ml}$, respectively. Therefore, consistent with the effective increase in the hepatic EPO mRNA levels induced by TP0463518 administration, the serum EPO concentrations were higher in the BNx rats than in the sham rats. These results demonstrated that TP0463518 induced hepatic EPO production and, in turn, increased liverderived EPO concentrations in the serum.

TP0463518 Has a Higher EPO-Inducing Potency in the Liver Than in the Kidney. To investigate whether the differential actions of TP0463518 on EPO expression between the liver and kidney are attributable to the difference in the exposure levels of TP0463518 between these organs, we measured the TP0463518 concentrations in each of these organs. In healthy rats, the TP0463518 concentrations at 4 hours postadministration were 5.3-6.4 and 17.5-23.5 times higher in the kidney and the liver compared with plasma, respectively (Table 2). To investigate the relationship between the TP0463518 concentrations and EPO mRNA expression levels, we plotted the EPO mRNA levels against the corresponding TP0463518 concentrations in the kidneys and liver. EPO mRNA expression in the liver increased in an exposuredependent manner (Fig. 5). In contrast, the EPO mRNA expression level in the kidney scarcely increased despite the increase of the TP0463518 concentration. At the same TP0463518 concentrations that yielded $5940 \mathrm{ng} / \mathrm{g}$ in the liver $(10 \mathrm{mg} / \mathrm{kg})$ and $5910 \mathrm{ng} / \mathrm{g}$ in the kidney $(40 \mathrm{mg} / \mathrm{kg})$, the EPO mRNA expressions increased by 185 -fold and 3.0-fold, respectively. These results demonstrated that TP0463518 exerted its EPO-producing effect almost exclusively in the liver and greatly contributed to augmentation of EPO levels in the serum.

Liver-Derived EPO Ameliorates Anemia. We next addressed whether liver-derived EPO induced by TP0463518 has ameliorating effects on anemia; we administrated TP0463518 to 5/6 Nx rats, which is a model of renal anemia. Although a single administration of TP0463518 at 10 or $20 \mathrm{mg} / \mathrm{kg}$ to $5 / 6 \mathrm{Nx}$ rats failed to increase the renal EPO mRNA expression, it markedly increased the hepatic EPO mRNA expression by 670 - and 1800 -fold, respectively, as compared with the level in the vehicle-treated group (Fig. 6). Therefore, in $5 / 6 \mathrm{Nx}$ rats, in which most of the kidney tissue has been removed, TP0463518 was not effective in inducing
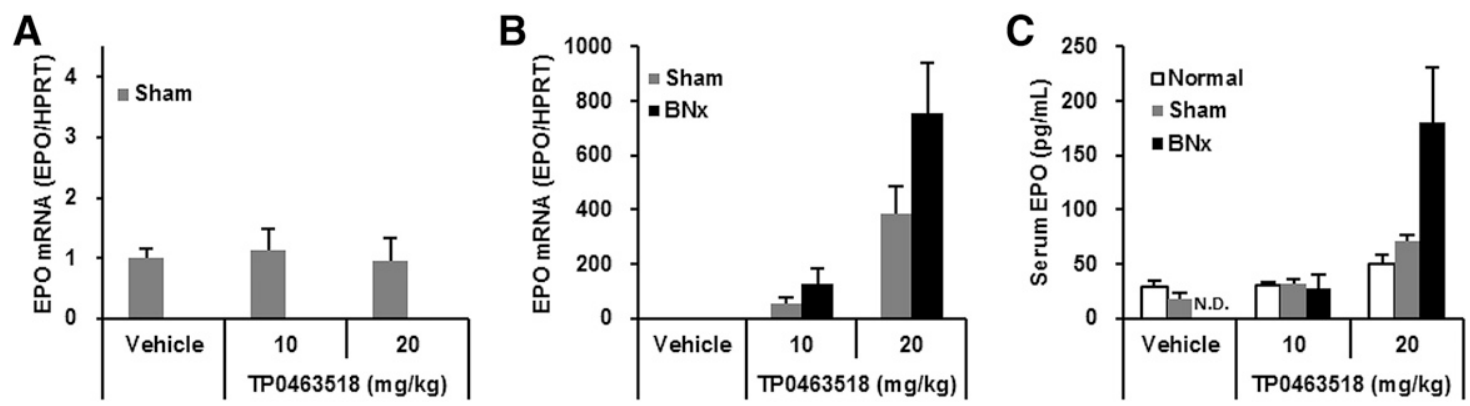

Fig. 4. The increase in the serum EPO after TP0463518 administration is mainly attributable to increased hepatic EPO production. (A and B) Renal and hepatic EPO mRNA expression levels in the sham and BNx rats. Real-time polymerase chain reaction analysis of the kidney and the liver was performed at 4 hours postadministration. (A) Renal EPO mRNA expression in the sham rats remained stable up to $20 \mathrm{mg} / \mathrm{kg}$ TP0463518. (B) Hepatic EPO mRNA expression levels in the sham and BNx rats increased in a dose-dependent manner. (C) Serum EPO concentrations in the normal, sham, and BNx rats. Elevated serum EPO concentrations in a dose-dependent manner were observed in each group at 8 hours postadministration. White bar, normal control rats; gray bar, sham rats; black bar, BNx rats. Data are represented as the means \pm S.E.M. $n=8-14$ (mRNA) or 6-8 (serum EPO). Serum EPO concentrations below detection limit were regarded as zero. N.D., not detected. 
TABLE 2

TP0463518 concentrations in the plasma, liver, and kidney at 4 hours after administration ( $\mathrm{ng} / \mathrm{ml}$ plasma or $\mathrm{g}$ tissue)

$\mathrm{L} / \mathrm{P}$ or K/P indicates the liver-plasma and kidney-plasma ratio of the TP0463518 concentrations. Mean \pm S.D., $n=6$.

\begin{tabular}{lcccc}
\hline \multicolumn{1}{c}{ Matrix } & $5 \mathrm{mg} / \mathrm{kg}$ & $10 \mathrm{mg} / \mathrm{kg}$ & $20 \mathrm{mg} / \mathrm{kg}$ & $40 \mathrm{mg} / \mathrm{kg}$ \\
\hline Plasma & $166 \pm 53.4$ & $337 \pm 120$ & $669 \pm 160$ & $1130 \pm 357$ \\
Liver & $3810 \pm 1090$ & $5940 \pm 1130$ & $11,700 \pm 1120$ & $20,300 \pm 9270$ \\
Kidney & $1040 \pm 324$ & $2040 \pm 790$ & $3810 \pm 1130$ & $5910 \pm 1690$ \\
Ratio (L/P) & $23.5 \pm 5.3$ & $18.8 \pm 5.9$ & $18.1 \pm 3.5$ & $17.5 \pm 2.8$ \\
Ratio (K/P) & $6.4 \pm 0.6$ & $6.0 \pm 0.7$ & $5.7 \pm 0.8$ & $5.3 \pm 0.4$ \\
\hline
\end{tabular}

renal EPO production up to $20 \mathrm{mg} / \mathrm{kg}$, unlike in normal rats.

In the $5 / 6 \mathrm{Nx}$ rats, although the reticulocyte count was similar to that in the sham rats $(263 \pm 8$ vs. $255 \pm 12$ billion cells/l), the hemoglobin concentration was significantly lower than that in the sham rats $(15.8 \pm 0.1$ vs. $13.4 \pm 0.3 \mathrm{~g} / \mathrm{dl})$, indicating that the $5 / 6 \mathrm{Nx}$ rats had anemia. After once-daily administration of TP0463518 for a week to these rats, the reticulocyte count increased in a dose-dependent manner, and the count was $481 \pm 23$ billion cells $/ \mathrm{l}$ at $10 \mathrm{mg} / \mathrm{kg}$ (Fig. 7A). The hemoglobin concentration in the vehicle-treated group was still low as compared with that in the sham rats after 2 weeks of repeated administration $(16.6 \pm 0.2$ vs. $14.2 \pm 0.4 \mathrm{~g} / \mathrm{dl})$. However, the hemoglobin concentration in the TP0463518treated groups increased in a dose-dependent manner, and the concentration reached $16.8 \pm 0.4 \mathrm{~g} / \mathrm{dl}$ at $10 \mathrm{mg} / \mathrm{kg}$ TP0463518, which was comparable to the hemoglobin concentration in the sham rats (Fig. 7B). The hematocrit increased from $41.4 \pm 1.2$ in the vehicle-treated group to $51.4 \% \pm 1.2 \%$ at $10 \mathrm{mg} / \mathrm{kg}$, becoming comparable to that in the sham rats $(49.1 \% \pm 0.7 \%)$ (Fig. 7C). The red blood cell count also increased from $7.40 \pm$ 0.24 to $8.80 \pm 0.20$ million cells $/ \mu \mathrm{l}(9.09 \pm 0.14$ million cells $/ \mu \mathrm{l}$ in the sham rats; Fig. 7D).

TP0463518 Increases EPO Expression in Human and Rat Cell Lines. To examine whether TP0463518 exerts EPO-producing effect in the liver cells, we addressed the effect of TP0463518 on EPO mRNA expression and EPO secretion in the human and rat liver cell lines, HepG2 and H4-II-E-C3. After the treatment of the cells with TP0463518 for 24 hours, EPO mRNA levels in both HepG2 and H4-II-E-C3 cells increased at $10 \mu \mathrm{M}$ or more; the increase at $30 \mu \mathrm{M}$ was 4.04- and 3.47-fold higher than control group, respectively (Fig. 8, A and B). EPO concentration in the medium of HepG2 cells treated with TP0463518 for 72 hours increased from $38.7 \mathrm{mU} / \mathrm{ml}$ in control wells to $74.0 \mathrm{mU} / \mathrm{ml}$ at $30 \mu \mathrm{M}$ (Fig. 8C). EPO concentration in medium of H4-II-E-C3 cells treated with TP0463518 for 72 hours also increased from $79.1 \mathrm{pg} / \mathrm{ml}$ in control wells to $254.9 \mathrm{pg} / \mathrm{ml}$ at $30 \mu \mathrm{M}$ (Fig. 8D). These results indicated that TP0463518 increased EPO expression not only in rat liver but also in human liver.

\section{Discussion}

TP0463518 is a PHD1/2/3 pan inhibitor and now under phase 1 clinical trials for renal anemia (Kato et al., 2018; Shinfuku et al., 2018). Based on previous findings, in this study, we investigated whether TP0463518 specifically induced EPO production in the liver. This study indicated that whereas TP0463518 did not induce HIF- $2 \alpha$-dependent EPO

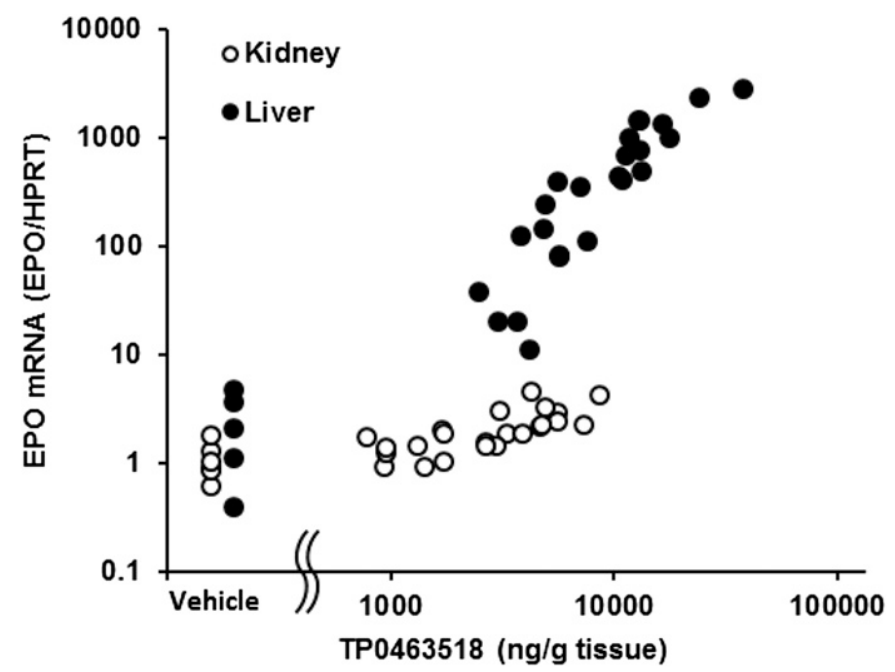

Fig. 5. TP0463518 increases EPO mRNA expression exclusively in the liver. Scatter plot of EPO mRNA expression levels against the TP0463518 concentrations. Individual EPO mRNA expression levels in the liver and kidney are plotted against the corresponding plasma TP0463518 concentrations ( $n=24$ in each organ). The EPO mRNA expression levels in the vehicle-treated group are plotted on the left ( $n=6$ in each organ). Athough EPO mRNA expression in the liver increased in an exposure-dependent manner, the EPO mRNA expression level in the kidney scarcely increased despite the increase of the TP0 463518 concentration. Open circles, kidney; filled circles, liver.

mRNA expression in the kidney, it markedly induced HIF- $2 \alpha$ and EPO mRNA expression in the liver. The different action of TP0463518 could not be ascribed to different TP0463518 concentrations between the kidney and liver. Consistent with the findings that TP0463518 increased hepatic EPO mRNA expression, the serum EPO concentrations in BNx rats increased to an extent comparable to or more than that in the sham rats. Furthermore, TP0463518 induced EPO mRNA

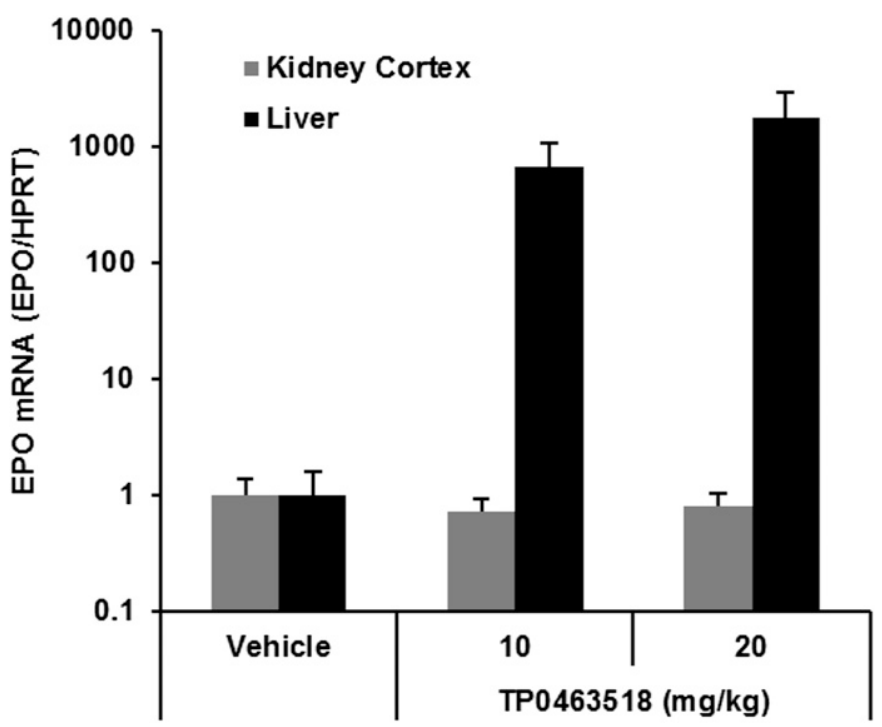

Fig. 6. Renal and hepatic EPO mRNA expressions in the $5 / 6 \mathrm{Nx}$ rats. Real-time polymerase chain reaction analysis of the kidney cortex and liver was performed at 2 hours postadministration. Renocortical EPO mRNA expression in the $5 / 6 \mathrm{Nx}$ rats remained stable up to $20 \mathrm{mg} / \mathrm{kg}$ TP0463518, whereas the hepatic EPO mRNA levels were elevated in a dose-dependent manner. Gray bar, kidney cortex; black bar, liver. Data are represented as the means \pm S.E.M. $n=5$. 
A
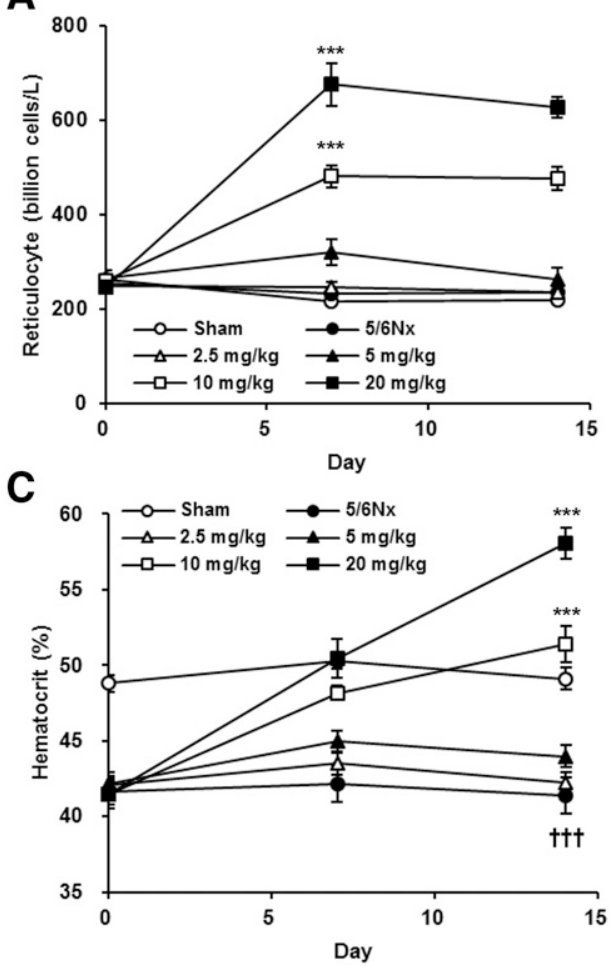

B

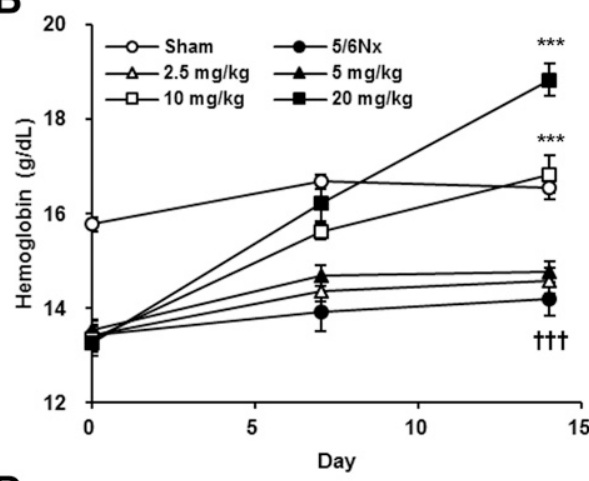

D

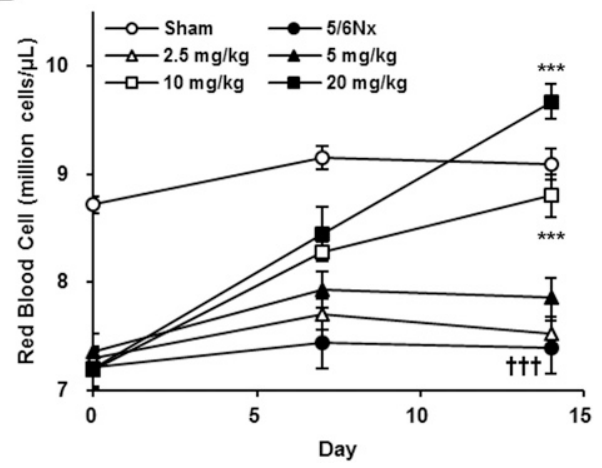

Fig. 7. TP0463518 ameliorates renal anemia. The reticulocyte count (A), hemoglobin level (B), hematocrit (C), and red blood cell count (D) were measured on days 0,7 , and 14 of treatment. TP0463518 raised all the parameters in a dose-dependent manner in the 5/6 Nx rats. Data are represented as the means \pm S.E.M. $n=9$ to 10 . Student's $t$ test was performed to compare the sham rats and $5 / 6 \mathrm{Nx}$ rats. $\dagger \dagger \dagger P<0.001$. Dunnett's multiple comparison test was used to compare the vehicle-treated $5 / 6$ $\mathrm{Nx}$ rats and TP0463518-treated groups. $* * * P<0.001$ expression only in the liver in $5 / 6 \mathrm{Nx}$ rats. These results thus clearly demonstrate that TP0463518 enhanced EPO production much more potent in the liver and increased the serum concentrations of EPO. We further demonstrated that liverderived EPO induced by TP0463518 was pharmacologically effective in ameliorating nephrectomy-induced anemia. Repeated administration of TP0463518 at $20 \mathrm{mg} / \mathrm{kg}$, although not increasing the renal EPO mRNA expression, greatly improved the hemoglobin levels in the $5 / 6 \mathrm{Nx}$ rats to the same degree or more than that in the sham rats in a dose-dependent manner. Therefore, TP0463518 is a liver-specific PHD
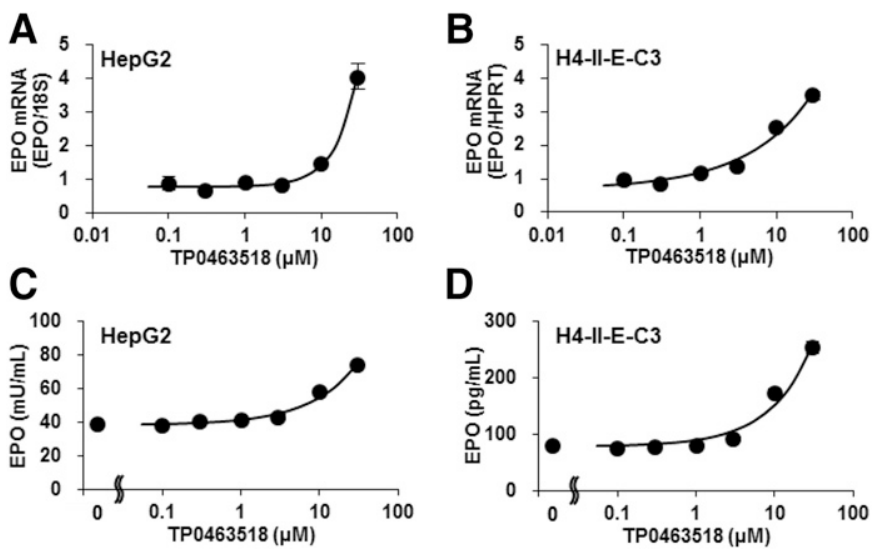

D

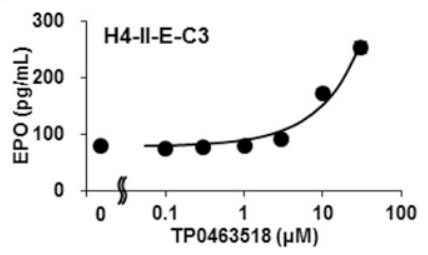

Fig. 8. TP0463518 increases the EPO mRNA expression and EPO concentration in the medium in HepG2 and H4-II-E-C3 cell lines. (A and B) EPO mRNA expression levels after the treatment with TP0463518 for 24 hours. TP0463518 increased the EPO mRNA expression levels in both (A) HepG2 and (B) H4-II-E-C3 cells at $10 \mu \mathrm{M}$ or more. (C and D) EPO concentration in medium after the treatment with TP0463518 for 72 hours. TP0463518 increased the EPO concentration in both (C) HepG2 and (D) H4-II-E-C3 cells at $10 \mu \mathrm{M}$ or more. Data are represented as the means \pm S.E.M. $n=3$. inhibitor at a therapeutic dose and has the potent ability to induce sufficient hepatic EPO production to ameliorate anemia. Additionally, TP0463518 increased EPO expression in human and rat cell lines, HepG2 and H4-II-E-C3. These results indicated that TP0463518 increased EPO expression not only in rat liver but also in human liver.

A number of studies have to date investigated the effects of genetic or pharmacological PHD suppression in animal models of nephropathy (Flamme et al., 2014; Souma et al., 2016). When unilateral ureteral obstruction was induced in knockout mice lacking PHD1/2/3, the EPO mRNA levels in the damaged kidney were higher than those in the healthy kidney (Souma et al., 2016). In contrast to these findings, the increase in renal EPO mRNA expression induced by a PHD inhibitor was significantly lower in gentamicin-induced nephropathic rats as compared with healthy control rats (Flamme et al., 2014). These findings suggest that the effects of a PHD inhibitor on the renal EPO production vary depending on the stage of nephropathy. Interestingly, hepatic EPO expression induced by a PHD inhibitor was reportedly almost comparable between gentamicin-induced nephropathic rats and healthy control rats (Flamme et al., 2014). There is no explicit evidence until date indicating that PHD inhibitors have the ability to stabilize HIF-2 $\alpha$ specifically in the liver and increase liverderived serum EPO concentrations. FG-2216 increased the serum EPO levels in anephric hemodialysis patients, but the increase of the serum EPO was smaller than that in nephric hemodialysis patients (Bernhardt et al., 2010). Molidustat was reported to increase the renal EPO mRNA expression in rats by several hundred fold, but raised hepatic EPO mRNA expression by only several 10 times (Flamme et al., 2014). Three other PHD inhibitors are now under phase 3 clinical trials (Coyne et al., 2017), but the main organ source of EPO production after administration of these inhibitors remains 
unknown. Therefore, to the best of our knowledge, TP0463518 is the only clinical compound inducing EPO specifically in the liver to ameliorate anemia.

TP0463518 scarcely induced EPO production in the kidney cortex despite the increase of the TP0463518 concentration. As kidney is a highly heterogeneous organ, the localization of the compound should be considered. The urinary excretion rates of FG-2216 and molidustat, which induced renal EPO, were $11 \%$ and $1.4 \%-3.6 \%$, respectively (Bernhardt et al., 2010; Böttcher et al., 2018). In contrast, the urinary excretion rate of TP0463518 was almost zero, and DMOG, which dominantly induced hepatic EPO, was metabolized in the liver (Hamada et al., 2018; Singh et al., 2019). Taking these points into consideration, a compound in the tubular might be delivered to the tubulointerstitium, and then the compound would exert EPO-producing effect in the kidney.

It is also noteworthy that liver-specific PHD1/2/3 tripleknockout mice reportedly increased hepatic EPO expression and developed polycythemia (Minamishima and Kaelin, 2010; Tojo et al., 2015). Furthermore, liver-derived EPO was also reported to cause polycythemia in liver-specific von HippelLindau protein knockout mice (Haase et al., 2001; Rankin et al., 2007). Higher hemoglobin level is associated with increased risk of stroke, cardiovascular events, and dialysis (Drüeke et al., 2006; Singh et al., 2006; Pfeffer et al., 2009). Therefore, it is crucial to ameliorate anemia without causing polycythemia. TP0463518 increased hemoglobin levels in the correction phase with a clear dose response from $2.5 \mathrm{mg} / \mathrm{kg}$, at which TP0463518 was ineffective, to $20 \mathrm{mg} / \mathrm{kg}$, at which TP0463518 was excessive. This result suggests that an adequate dose adjustment of TP0463518 could control hemoglobin levels within desirable range in the maintenance phase. TP0463518 is now being examined in a clinical trial, and the clinical proof of concept will be available in the future.

The present study thus revealed a very unique feature of TP0463518, in that TP0463518 stabilized HIF-2 $\alpha$ and induced EPO specifically in the liver at a therapeutic dose. Furthermore, TP0463518 improved the hemoglobin level to within normal range with a good dose response, and was expected to allow hemoglobin levels to be maintained in the normal range over the long term without causing polycythemia. Therefore, the characteristic feature of TP0 463518 would lead to not only a more detailed understanding of the PHD-HIF2-EPO pathway in erythropoiesis, but also a new therapeutic alternative for renal anemia in patients with chronic kidney disease.

\section{Acknowledgments}

We thank Dr. Shigetada Nakanishi, Dr. Yoshiki Fukasawa, and Dr. Shigeyuki Chaki for valuable suggestions during the preparation of this manuscript, and Chie Koizumi, Yosuke Nakamura, and Tore Eriksson for technical support.

\section{Authorship Contributions}

Participated in research design: Kato, Kunioka, Uchida.

Conducted experiments: Kato, Ochiai, Takano, Io, Takayama, Koretsune, Kunioka.

Performed data analysis: Kato, Ochiai.

Wrote or contributed to the writing of the manuscript: Kato, Takano, Yamamoto.

\section{References}

Ariazi JL, Duffy KJ, Adams DF, Fitch DM, Luo L, Pappalardi M, Biju M, DiFilippo EH, Shaw T, Wiggall K, et al. (2017) Discovery and preclinical characterization of GSK1278863 (daprodustat), a small molecule hypoxia inducible factor-prolyl hydroxylase inhibitor for anemia. J Pharmacol Exp Ther 363:336-347.

Asada N, Takase M, Nakamura J, Oguchi A, Asada M, Suzuki N, Yamamura K, Nagoshi N, Shibata S, Rao TN, et al. (2011) Dysfunction of fibroblasts of extrarenal origin underlies renal fibrosis and renal anemia in mice. $J$ Clin Invest 121: 3981-3990.

Bernhardt WM, Wiesener MS, Scigalla P, Chou J, Schmieder RE, Günzler V, and Eckardt KU (2010) Inhibition of prolyl hydroxylases increases erythropoietin production in ESRD. J Am Soc Nephrol 21:2151-2156.

Böttcher M, Lentini S, Arens ER, Kaiser A, van der Mey D, Thuss U, Kubitza D, and Wensing G (2018) First-in-man-proof of concept study with molidustat: a novel selective oral HIF-prolyl hydroxylase inhibitor for the treatment of renal anaemia. Br J Clin Pharmacol 84:1557-1565.

Coyne DW, Goldsmith D, and Macdougall IC (2017) New options for the anemia of chronic kidney disease. Kidney Int Suppl (2011) 7:157-163.

Dame C, Fahnenstich H, Freitag P, Hofmann D, Abdul-Nour T, Bartmann P, and Fandrey J (1998) Erythropoietin mRNA expression in human fetal and neonatal tissue. Blood 92:3218-3225.

Dao JH, Kurzeja RJ, Morachis JM, Veith H, Lewis J, Yu V, Tegley CM, and Tagari $\mathrm{P}$ (2009) Kinetic characterization and identification of a novel inhibitor of hypoxia-inducible factor prolyl hydroxylase 2 using a time-resolved fluorescence resonance energy transfer-based assay technology. Anal Biochem 384:213-223.

Drüeke TB, Locatelli F, Clyne N, Eckardt KU, Macdougall IC, Tsakiris D, Burger HU, and Scherhag A; CREATE Investigators (2006) Normalization of hemoglobin level in patients with chronic kidney disease and anemia. $N$ Engl J Med $\mathbf{3 5 5}$ 2071-2084.

Eckardt KU, Ratcliffe PJ, Tan CC, Bauer C, and Kurtz A (1992) Age-dependent expression of the erythropoietin gene in rat liver and kidneys. $J$ Clin Invest 89: $753-760$.

Flamme I, Oehme F, Ellinghaus P, Jeske M, Keldenich J, and Thuss U (2014) Mimicking hypoxia to treat anemia: HIF-stabilizer BAY 85-3934 (Molidustat) stimulates erythropoietin production without hypertensive effects. PLoS One 9: e111838.

Haase VH (2006) Hypoxia-inducible factors in the kidney. Am J Physiol Renal Physiol 291:F271-F281.

Haase VH (2017) Oxygen sensors as therapeutic targets in kidney disease. Nephrol Ther 13 (Suppl 1):S29-S34.

Haase VH, Glickman JN, Socolovsky M, and Jaenisch R (2001) Vascular tumors in livers with targeted inactivation of the von Hippel-Lindau tumor suppressor. Proc Natl Acad Sci USA 98:1583-1588.

Hamada M, Takayama T, Shibata T, Hiratate A, Takahashi M, Yashiro M, Takayama N, Okumura-Kitajima L, Koretsune H, Kajiyama H, et al. (2018) Discovery of novel 2-[(4-hydroxy-6-oxo-2,3-dihydro-1H-pyridine-5-carbonyl)amino] acetic acid derivatives as HIF prolyl hydroxylase inhibitors for treatment of renal anemia. Bioorg Med Chem Lett 28:1725-1730.

Hirsilä M, Koivunen P, Günzler V, Kivirikko KI, and Myllyharju J (2003) Characterization of the human prolyl 4-hydroxylases that modify the hypoxia-inducible factor. J Biol Chem 278:30772-30780.

Jaakkola P, Mole DR, Tian YM, Wilson MI, Gielbert J, Gaskell SJ, von Kriegsheim A, Hebestreit HF, Mukherji M, Schofield CJ, et al. (2001) Targeting of HIF-alpha to the von Hippel-Lindau ubiquitylation complex by O2-regulated prolyl hydroxylation. Science 292:468-472.

Kapitsinou PP, Liu Q, Unger TL, Rha J, Davidoff O, Keith B, Epstein JA, Moores SL, Erickson-Miller CL, and Haase VH (2010) Hepatic HIF-2 regulates erythropoietic responses to hypoxia in renal anemia. Blood 116:3039-3048.

Kato S, Takayama N, Takano H, Koretsune H, Koizumi C, Kunioka EI, Uchida S, Takahashi T, and Yamamoto K (2018) TP0463518, a novel inhibitor for hypoxiainducible factor prolyl hydroxylases, increases erythropoietin in rodents and monkeys with a good pharmacokinetics-pharmacodynamics correlation. Eur $J$ Pharmacol 838:138-144.

Koury MJ and Haase VH (2015) Anaemia in kidney disease: harnessing hypoxia responses for therapy. Nat Rev Nephrol 11:394-410.

Kuhrt D and Wojchowski DM (2015) Emerging EPO and EPO receptor regulators and signal transducers. Blood 125:3536-3541.

Ladroue C, Carcenac R, Leporrier M, Gad S, Le Hello C, Galateau-Salle F, Feunteun J, Pouysségur J, Richard S, and Gardie B (2008) PHD2 mutation and congenital erythrocytosis with paraganglioma. N Engl J Med 359:2685-2692.

Maxwell PH, Wiesener MS, Chang GW, Clifford SC, Vaux EC, Cockman ME, Wykoff CC, Pugh CW, Maher ER, and Ratcliffe PJ (1999) The tumour suppressor protein VHL targets hypoxia-inducible factors for oxygen-dependent proteolysis. Nature 399:271-275.

Minamishima YA and Kaelin WG Jr (2010) Reactivation of hepatic EPO synthesis in mice after PHD loss. Science 329:407.

Minamishima YA, Moslehi J, Padera RF, Bronson RT, Liao R, and Kaelin WG Jr (2009) A feedback loop involving the Phd3 prolyl hydroxylase tunes the mammalian hypoxic response in vivo. Mol Cell Biol 29:5729-5741.

Pappalardi MB, McNulty DE, Martin JD, Fisher KE, Jiang Y, Burns MC, Zhao H, Ho T, Sweitzer S, Schwartz B, et al. (2011) Biochemical characterization of human HIF hydroxylases using HIF protein substrates that contain all three hydroxylation sites. Biochem J 436:363-369.

Percy MJ, Furlow PW, Beer PA, Lappin TR, McMullin MF, and Lee FS (2007) A novel erythrocytosis-associated PHD2 mutation suggests the location of a HIF binding groove. Blood 110:2193-2196.

Percy MJ, Zhao Q, Flores A, Harrison C, Lappin TR, Maxwell PH, McMullin MF and Lee FS (2006) A family with erythrocytosis establishes a role for prolyl hydroxylase domain protein 2 in oxygen homeostasis. Proc Natl Acad Sci USA 103: 654-659.

Pfeffer MA, Burdmann EA, Chen CY, Cooper ME, de Zeeuw D, Eckardt KU, Feyz JM, Ivanovich P, Kewalramani R, Levey AS, et al.; TREAT Investigators (2009) 
A trial of darbepoetin alfa in type 2 diabetes and chronic kidney disease. $N$ Engl J Med 361:2019-2032.

Rankin EB, Biju MP, Liu Q, Unger TL, Rha J, Johnson RS, Simon MC, Keith B and Haase VH (2007) Hypoxia-inducible factor-2 (HIF-2) regulates hepatic erythropoietin in vivo. J Clin Invest 117:1068-1077.

Shinfuku A, Shimazaki T, Fujiwara M, Sato F, Watase H, Numazaki T, Kawakita Y, Mutoh M, Yamasaki H, Takayama N, et al. (2018) Novel compound induces erythropoietin secretion through liver effects in chronic kidney disease patients and healthy volunteers. Am J Nephrol 48:157-164.

Singh AK, Szczech L, Tang KL, Barnhart H, Sapp S, Wolfson M, and Reddan D CHOIR Investigators (2006) Correction of anemia with epoetin alfa in chronic kidney disease. N Engl J Med 355:2085-2098.

Singh C, Hoppe G, Tran V, McCollum L, Bolok Y, Song W, Sharma A, Brunengraber $\mathrm{H}$, and Sears JE (2019) Serine and 1-carbon metabolism are required for HIFmediated protection against retinopathy of prematurity. JCI Insight 4:129398.

Souma T, Nezu M, Nakano D, Yamazaki S, Hirano I, Sekine H, Dan T, Takeda K, Fong GH, Nishiyama A, et al. (2016) Erythropoietin synthesis in renal myofibroblasts is restored by activation of hypoxia signaling. J Am Soc Nephrol 27: 428-438.

Souma T, Yamazaki S, Moriguchi T, Suzuki N, Hirano I, Pan X, Minegishi N, Abe M, Kiyomoto H, Ito S, et al. (2013) Plasticity of renal erythropoietin-producing cells governs fibrosis. J Am Soc Nephrol 24:1599-1616.

Takeda K, Aguila HL, Parikh NS, Li X, Lamothe K, Duan LJ, Takeda H, Lee FS, and Fong GH (2008) Regulation of adult erythropoiesis by prolyl hydroxylase domain proteins. Blood 111:3229-3235.
Tan CC, Eckardt KU, Firth JD, and Ratcliffe PJ (1992) Feedback modulation of renal and hepatic erythropoietin mRNA in response to graded anemia and hypoxia. Am $J$ Physiol 263:F474-F481.

Tea M, Fogarty R, Brereton HM, Michael MZ, Van der Hoek MB, Tsykin A, Coster DJ, and Williams KA (2009) Gene expression microarray analysis of early oxygeninduced retinopathy in the rat. J Ocul Biol Dis Infor 2:190-201.

Tojo Y, Sekine H, Hirano I, Pan X, Souma T, Tsujita T, Kawaguchi S, Takeda N, Takeda K, Fong GH, et al. (2015) Hypoxia signaling cascade for erythropoietin production in hepatocytes. Mol Cell Biol 35:2658-2672.

Vandesompele J, De Preter K, Pattyn F, Poppe B, Van Roy N, De Paepe A and Speleman F (2002) Accurate normalization of real-time quantitative RT-PCR data by geometric averaging of multiple internal control genes. Genome Biol $\mathbf{3}$ RESEARCH0034.

Wigestrand MB, Mineur YS, Heath CJ, Fonnum F, Picciotto MR, and Walaas SI (2011) Decreased $\alpha 4 \beta 2$ nicotinic receptor number in the absence of mRNA changes suggests post-transcriptional regulation in the spontaneously hypertensive rat model of ADHD. J Neurochem 119:240-250.

Zanjani ED, Ascensao JL, McGlave PB, Banisadre M, and Ash RC (1981) Studies on the liver to kidney switch of erythropoietin production. $J$ Clin Invest 67:1183-1188.

Address correspondence to: Dr. Sota Kato, Pharmacology Laboratories, Taisho Pharmaceutical, 1-403 Yoshino-cho, Kita-ku, Saitama 331-9530, Japan.

E-mail: so-katou@taisho.co.jp 